\title{
Stimulation of Neural Cells by Lateral Currents in Conductive Layer-by-Layer Films of Single-Walled Carbon Nanotubes**
}

\author{
By Muhammed K. Gheith, Todd C. Pappas, Anton V. Liopo, Vladimir A. Sinani, Bong Sup Shim, \\ Massoud Motamedi, James P. Wicksted, and Nicholas A. Kotov*
}

Single-walled carbon nanotubes (SWNTs) have a set of unique mechanical and electrical properties that has stimulated tremendous interest in them. Significant efforts have been directed towards utilizing these materials as building blocks of composites for a variety of technological contexts, such as nanoelectronic devices, ${ }^{[1-6]}$ sensors, ${ }^{[7-12]}$ and field emission electron displays and lighting elements. ${ }^{[13,14]}$ We strongly believe that one of the most prolific areas of their applications will be in biomedicine, where compact, strong, and high-performance devices can be engineered. These devices will exploit the properties of SWNTs and will compete with existing products. The novel technologies of diagnostics and therapeutics can be based on SWNT composites and individual tubes. Along these lines, SWNTs have been demonstrated as potential sensing materials of biological systems, ${ }^{[15-19]}$ which are typically considered for the use in ex vivo modality. The potential use of SWNT-based structures for the purpose of healing neurological and brain-related injuries represents one of the major scientific and practical interests. The high mechanical strength and electrical properties possessed by SWNTs makes these materials perfect candidates for various prosthetic devices, including bone and joint repair. It is important to realize, however, that successful utilization of SWNT-based devices in biomedicine is hinged on the ability of such materials to interface with living cells, support their growth, and at

[*] Prof. N. A. Kotov, Dr. V. A. Sinani, B. S. Shim Department of Chemical Engineering, Department of Biomedical Engineering, Department of Materials Science University of Michigan

2300 Hayward St., Ann Arbor, MI 48109-2136 (USA)

E-mail: kotov@umich.edu

M. K. Gheith, ${ }^{[+]}$Prof. J. P. Wicksted

Department of Physics

Oklahoma State University

145 Physical Sciences Building, Stillwater, OK 74078-3072 (USA)

Prof. T. C. Pappas, Dr. A. V. Liopo, Prof. M Motamedi

Center for Biomedical Engineering

University of Texas Medical Branch

Jennie Sealy Hospital, Galveston, TX 77555-0144 (USA)

[+] Present address: Department of Electrical and Computer Engineering, Rice University, Houston, TX 77005, USA.

$[* *$ ] The authors thank the funding agencies including NSF BioPhotonics (BES-0119483 NAK, BES $0119544 \mathrm{MM}$ ), NSF CAREER award CHE-9876265 NAK) and NSF EPSCoR grant EPS-0132534. The authors thank Prof. Alexander A. Yaroslavov (M. V. Lomonosov Moscow State University) for his kind supply of the amphiphilic polymer used in the study. MKG and NAK thank Ms. Phoebi Doss for her assistance with SEM samples preparation. the same time preserve their viability. ${ }^{[20-24]}$ These factors are not well understood for any SWNT structures, which limits the development of in vivo, that is, implantable devices from such materials.

The actual processes and techniques used for the preparation of macroscopic objects from SWNTs will play a significant role in determining cellular effects of SWNT composites. Substrates prepared from multi-walled carbon nanotubes (MWNTs) as well as SWNTs have been reported to be biocompatible platforms for neuronal growth and differentiation. ${ }^{[25-27]}$ The use of carbon nanofiber composites as devices for neural- and bone-tissue-implant integration has also been described. ${ }^{[28]}$ Molecular engineering of any SWNT-based composite should have a great effect on how the material performs during long-term contact with tissue. The layer-by-layer (LBL) approach to prepare SWNT structures can be particularly useful in this respect because it allows one to exert control over the structure of the SWNT/polymer systems from angstrom to nanometer and micrometer scale, which is necessity for the engineering of the cell/SWNT interface. ${ }^{[29]} \mathrm{Re}$ cently, we demonstrated that SWNT LBL films can support the growth, viability, and differentiation of neuronal NG10815 neuroblastoma/glioma hybrid cells. ${ }^{[30]}$ The first example of free-standing SWNT/polymer thin-film membranes that can be mechanically compatible with tissues and can be used as implants and repair devices for neurological- or brain-related injuries has been demonstrated. ${ }^{[30]}$ The free-standing SWNT/ polyelectrolyte multilayers can serve as a prototype for a variety of nanotube-based implants.

As the next logical step in studying the capabilities of SWNT multilayers, we demonstrate here the possibility of utilizing the electrical conductivity of LBL-assembled, modified SWNT films to stimulate the neurophysiological activity of NG108-15 cells. Stimulation of neurons through SWNT composites has never been demonstrated before on any SWNT composites or related materials, and therefore, is significant for the further development of bio-nanotechnology of carbon nanotubes. Compared to previous approaches to SWNT-composite preparation, ${ }^{[31,32]}$ multilayer films offer simplicity and structural flexibility for the preparation of highly conductive films of SWNTs that, in perspective, will afford systematic investigation of cell-SWNT interactions. In our view, the possibility to tune the biological activity of the films, and thus, their interaction with the cells can be particularly attractive. From a practical perspective, the mechanical properties ${ }^{[33-35]}$ of the LBL composites when high-aspect-ratio components incorporated can be particularly attrac- 
tive for the production of long-term biomedical healing and therapeutic devices of different tissue. ${ }^{[36,37]}$

The LBL films of SWNT were made from positively charged nanotubes coated with a designer copolymer allowing excellent SWNT and MWNT dispersion. ${ }^{[38]}$ A total of 30 multilayers were deposited on a glass slide producing a $\left(\mathrm{PAA}^{-} /\right.$ $\left.\mathrm{SWNT}^{+}\right)_{30}$ LBL film (PAA: poly(acrylic acid)). The prepared LBL films from SWNTs were found to be conductive because of the high loading of nanotubes, the extensive percolation network, and the close contacts between nanotubes in alternating layers that are necessary for efficient charge transport. ${ }^{[39]}$ The coating formed by poly $(N$-cetyl-4-vinylpyridinium bromide-co- $\mathrm{N}$-ethyl-4-vinylpyridinium bromide-co-4vinylpyridine) around SWNTs is relatively thick. So, the conductances of the multilayers used here $\left(119 \mathrm{~S} \mathrm{~cm}^{-1}\right)$ were lower than for bucky paper (ca. $10^{4} \mathrm{~S} \mathrm{~cm}^{-1}$ ). As we shall see below, the resistive nature of the film can actually be used as an advantage in the set-up, reminiscent of the field-effect transistor (FET).$^{[40,41]}$ On one hand, it allows for some current to be directed through the bath and into the cells, whereas on the other hand, it makes it possible, in perspective, to create a two-way communication system with neurons where the lateral current will be affected by the excitation state of the cells. In this work, we aimed to detect clear evidence of electrophysiological activity taking place through the membrane of neuronlike NG108-15 cells upon stimulation through the SWNT coating.

A special substrate was designed in order to obtain electrophysiological measurements on the communication between neuron cells and SWNT LBL films (Fig. 1). A standard indium tin oxide (ITO)-coated glass slide $(25 \mathrm{~mm} \times 50 \mathrm{~mm} \times 1.1 \mathrm{~mm}$, Delta Technologies, USA) was patterned to remove the conductive ITO layer from a $15 \mathrm{~mm} \times 25 \mathrm{~mm}$ wide strip in the middle of the slide (Fig. 1). The (PAA $\left.{ }^{-} / \mathrm{SWNT}^{+}\right)_{30}$ multilayers

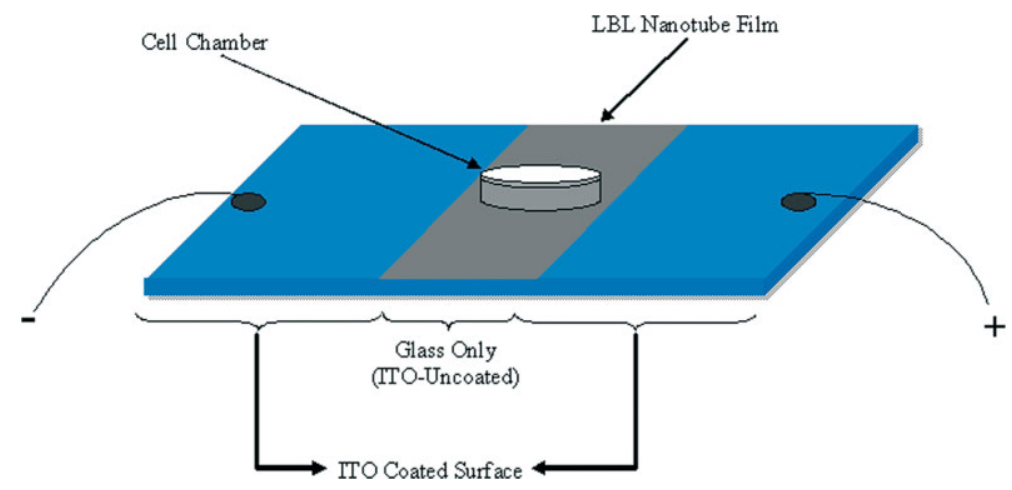

Figure 1. Illustration of the substrate used as an electrical cell for stimulating NG10815 cells. Blue-colored areas correspond to ITO-coated glass surfaces. Area labeled "glass only" represents the surface area on the ITO substrate that was treated with concentrated $\mathrm{HCl}$ to remove the ITO coating (middle of the slide). The rectangular gray area on top of the slide represents the LBL film assembled on the treated, nonconductive area bridging the two untreated, conductive, ITO-coated parts of the substrate. Cells were seeded and differentiated in a cell chamber mounted on the assembled SWNT film. External potential was applied and maintained across the substrate via two silver electrodes that were mounted on both sides of the substrate in direct contact with the ITO-coated sides. were assembled over the naked glass section, bridging the gap between the two conductive ITO-coated sections. The ITOcoated sides were used solely as conductive electrodes, where a constant potential difference could be applied when necessary, and maintained across the SWNT LBL film via two silver wires that were connected directly to the ITO areas (Fig. 1). Cells were seeded in a specially designed chamber mounted on the SWNT LBL film without contact to the ITO sections (Fig. 1). This was done in order to create a device where external stimulation through the substrate is carried by the SWNT film only.

Differentiation of NG108-15 cells is essential for electrophysiological investigations. Similar to neurons and other excitable cells, differentiated NG108-15 cells usually exhibit excitable membranes. They show strong ion currents modulated by voltage-activated ion channels, which make this cell culture quite convenient for basic research on the neuron interface. ${ }^{[42]}$ Cell differentiation was induced by incubating the cells (for 5-7 days) in a culture medium consisting of Dulbecco's Modified Eagle's Medium (DMEM), $1 \%$ fetal bovine serum (FBS), HAT supplement ( $0.1 \mathrm{~mm}$ hypoxanthine, $400 \mathrm{~nm}$ aminopterin, $0.016 \mathrm{~mm}$ thymidine), $0.5 \%$ penicillin/streptomycin, $5 \mu \mathrm{M}$ forskolin, and $5 \mu \mathrm{M}$ isobutyl methyl xanthine, under a humidified environment at $37^{\circ} \mathrm{C}$. The use of forskolin and isobutyl methyl xanthine supplement is particularly essential to enhance the activity of cyclic adenosine $5^{\prime}$-monophosphate (cAMP), which is necessary to drive the differentiation of these cells. ${ }^{[43]}$

The successful electrical stimulation of NG108-15 cells depends on the ability of these cells to attach to the surface of the nanotube films. ${ }^{[30]}$ Figure 2 shows a scanning electron microscopy image of a differentiated NG108-15 cell on the surface of a modified SWNT LBL structure. These cells extend long neurites that develop into many secondary processes, branching in many directions on the surface. Since the original shape of the NG105-15 cells is round and fairly small, such a morphology is clear evidence of successful differentiation of the cells. Previous studies also demonstrated their excellent viability on the SWNT LBL films. ${ }^{[30]}$ In the framework of this project, we want to point out the large surface area of the electrical contact with the film provided by the long neurites, which is a prerequisite for efficient stimulation.

Electrophysiological measurements were conducted using a voltage/patch clamp technique. Cells were voltage clamped using single patch electrodes in the whole-cell mode, which means that the thin pipette penetrated the cell membrane, effectively connecting the metal electrode in the upper part of the pipette to the internal volume of the cell. The potential measured in this mode corresponds to the transmembrane potential of the whole cell. It also allows one to change the potential while registering the corresponding current necessary for maintaining a certain voltage drop across the membrane. The potential between the 


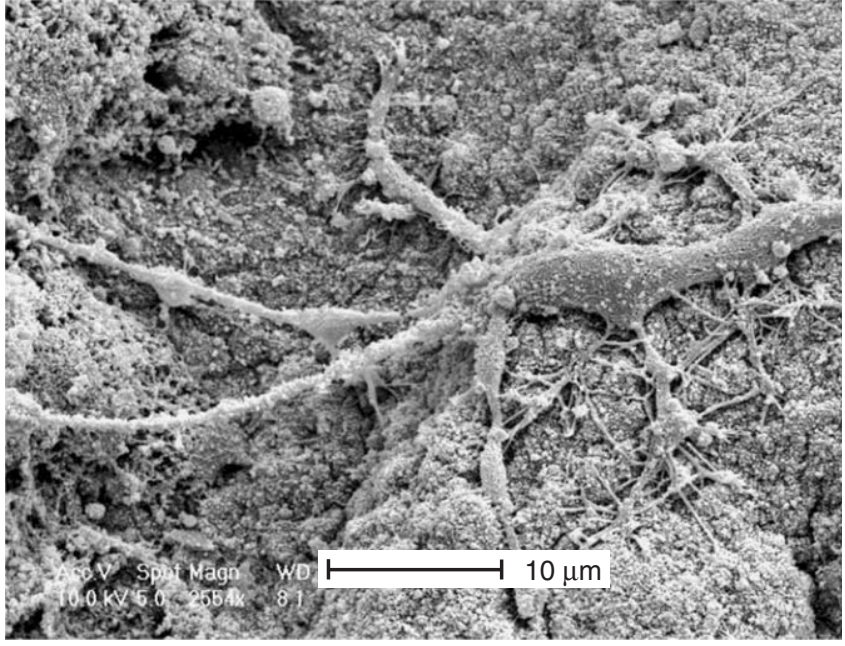

Figure 2. Scanning electron microscopy image of a differentiated NG10815 cell on a SWNT LBL film showing the outgrowth of neurites and branches that attach to the surface. Scale bar: $10 \mu \mathrm{m}$.

pipette electrode and the reference electrode in the bath was held at $-60 \mathrm{mV}$, which is close to the resting potential of the NG108-15 cells, using an SEC-05LX amplifier (NPI Electronics $\mathrm{GmbH}$, Tamm, Germany) interfaced to a computer using an ITC-18 interface (Instrutech Corp.). This set-up allowed for the accurate detection of flowing currents through the whole cell membrane as a response to voltage pulses through the LBL film.

Prior to stimulating the cells through the SWNT multilayers, we first examined their standard electrophysiological response as a blank experiment. The measurements of input resistance obtained for cells grown on nanotube films $(122 \pm 55 \mathrm{M} \Omega, 9$ cells) were virtually identical to those obtained for cells cultured on bare glass $(140 \pm 67 \mathrm{M} \Omega, 6$ cells), which indicates that the cellular health was unperturbed by the SWNT substrates. Figure 3 shows current traces measured from NG108-15 cells differentiated on the SWNT LBL multilayers and stimulated intrinsically through the pipette electrode in the whole-cell voltage-clamp configuration. Currents were evoked with a $10 \mathrm{mV}$ increment voltage step over a $20 \mathrm{~ms}$ period starting from a $-65 \mathrm{mV}$ holding potential (insets). The current transients show that NG108-15 cells differentiated on nanotube film have temporal and reversal behavior typical for inward currents determined by voltageactivated $\mathrm{Na}^{+}$channels. ${ }^{[44]}$ Inward $\mathrm{Na}^{+}$currents are characterized by the negative deflections in the current trace over time, followed by a rapid decay. The dependence of the peak inward currents (marked with an asterisk in Fig. 3A) on the excitation voltage shows the activation threshold at approximately $-30 \mathrm{mV}$ (Fig. 3B), which is typical for healthy neurons. As expected, the inward $\mathrm{Na}^{+}$currents could be reversibly inactivated by the addition of $100 \mathrm{~nm}$ tetrodotoxin (TTX; a blocker of voltage-activated sodium channel), which confirms the assignment of the currents and the fact that NG108-15 cells have excitation behavior on SWNT substrates identical
A.

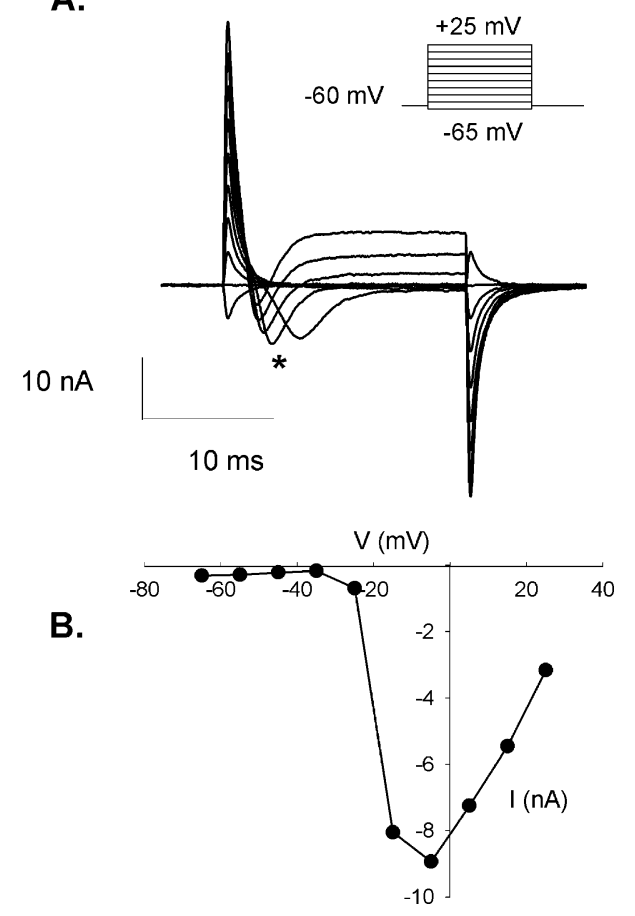

Figure 3. A) Currents evoked by the intrinsic voltage change of NG10815 cells recorded in the whole-cell voltage-clamp configuration during pipette electrode stimulation. Following a brief pipette-electrode artifact associated with the voltage jump from the holding potential of $-65 \mathrm{mV}$ (first $1 \mathrm{~ms}$ ), whole-cell currents of the NG108-15 cells stepped to $\geq-35 \mathrm{mV}$ show a rapid negative (inward) current (asterisk). After that, it rapidly inactivates $(<5 \mathrm{~ms})$ and the remaining whole-cell currents, which are probably "leak" channels, reach a plateau. Following this, another spike artifact is associated with releasing the holding voltage. Currents are measured over time according to the current scale shown in response to a $10 \mathrm{mV}$ increment voltage step (inset) from a $-60 \mathrm{mV}$ holding potential. B) Representative current-voltage $(I-V)$ relationship at peak inward currents from (A).

to that on any other classical substrates used before. In other words, SWNT LBL films can maintain NG108-15 cells in a physiologically differentiated state similar to the natural state of neurons, ${ }^{[30]}$ which is crucial for high membrane excitability. ${ }^{[45]}$

We attempted to stimulate the cells by passing current through the nanotube film. Figure 4 illustrates the inward cellular currents evoked by two separate stimulations across the nanotube film. It is evident that the shape of the transients resembles that of the whole-cell stimulation curves obtained for intrinsic excitation with an inserted pipette electrode. These representative currents were evoked by $100 \mathrm{~ms}, 1-2 \mu \mathrm{A}$ pulses across the nanotube film at $1 \mathrm{~Hz}$. Following an initial capacitive charging artifact (sharp positive spike; Fig. 4), cells show robust inward $\mathrm{Na}^{+}$currents (Fig. 4, asterisks) that are similar in magnitude and duration to those evoked by step changes in membrane potential (Fig. 3A). All cells that showed inward currents with step voltage changes, as in Figure 3, could also be stimulated via extrinsic stimulation through the SWNT film. These observations are evidence of the natural electrical response of the cells to excitation through the laterally ap- 
A.

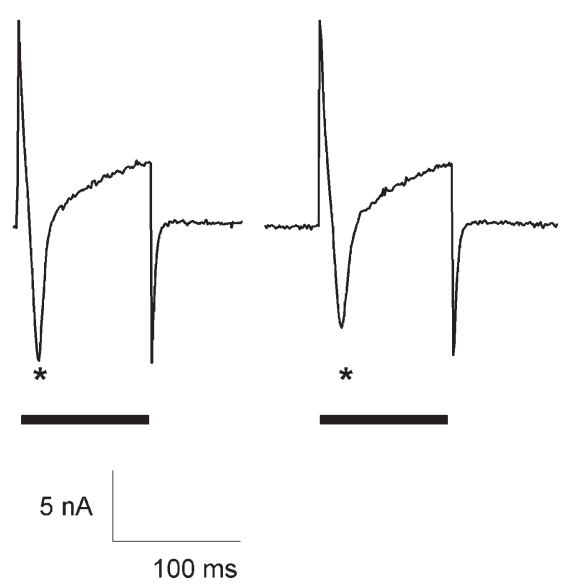

B.

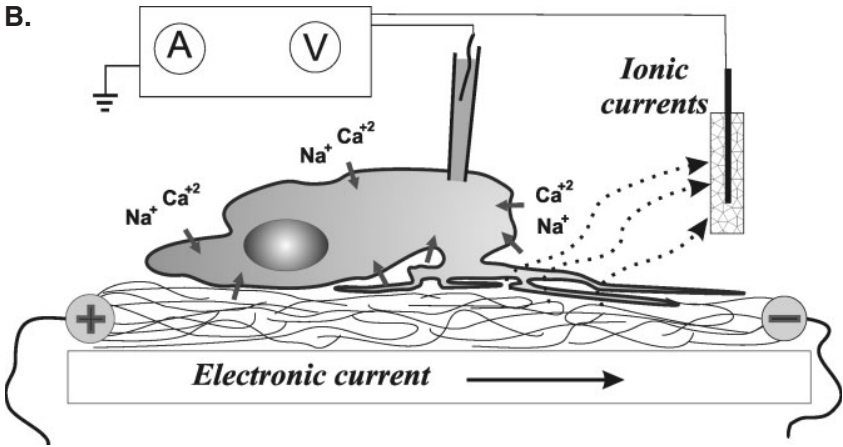

Figure 4. A) Two independent, representative current traces (over time) from NG108-15 cells stimulated by extrinsic current passed through the SWNT film $(100 \mathrm{~ms}, 1 \mathrm{~Hz})$ and recorded in whole-cell voltage clamp mode. Note that the lateral current through SWNT film results in rapid inward currents (asterisk) indicative of $\mathrm{Na}^{+}$ion currents from Figure $3 \mathrm{~A}$. B) Schematics of the neuron excitation in the SWNT layer by lateral current. Arrows in the neuron membrane indicate ion opening channels.

plied voltage to the nanotube film, and indicate that SWNT LBL films can be used to electrically stimulate significant ion conductances in neuronal cells. The direction of the electrophysiological response and the time-course study suggest that cells are stimulated by the influx of cations in the cells. Even though most of the charges in the lateral excitation are transferred between the ITO electrodes (Fig. 1), a small current is generated between the LBL film and the $\mathrm{Ag} / \mathrm{AgCl}$ electrode in the bath serving as a counterpart for the voltage-clamp pipette electrode inserted in the cells. The associated ionic flux passes through the membrane of the cell because of good attachment and a high degree of differentiation of neurons (Fig. 1). Since the membrane has a high resistance of 100 $500 \mathrm{M} \Omega$, this small current results in substantial change of the potential of the cell membrane. To a large extent, this is similar to the excitation by extrinsic current flow. ${ }^{[46]}$ The electrical configuration used here, employing the application of the lateral voltage rather than direct transversal excitation, with a SWNT film as one of the electrodes, is convenient because, in perspective, it affords both excitation and sensing of the neuronal processes in a manner different from the case of the field-effect transistor set-up used before. ${ }^{[41]}$ The switch between the two modes can be easily achieved by disconnecting the bath electrode from the electrical circuit or simply by varying the current through the SWNT film. Further studies are needed to determine if there is capacitive coupling ${ }^{[40]}$ of the neuron to the nanotube surfaces, which would allow for extremely rapid and highly controllable stimulation and recording on these substrates.

In summary, SWNTs can be incorporated into LBL multilayers with sufficiently high electrical conductivity to electrically stimulate excitable neuronal cells. Using SWNT LBL films as culturing substrates did not perturb the key electrophysiological features of NG108-15 cells, which confirms previous observations with a different nanotube material. ${ }^{[32]}$ Electrophysiological measurements demonstrate a clear signature of electrical excitation of neurons when current is passed through the LBL coating that is identical with traditional means of neuron excitation and can be associated with opening of voltage-activated cation channels. Fundamentally, this is important evidence of electrical coupling between SWNT-based LBL films and NG108-15 cells in the lateral electrical configuration, which can be quite convenient for medical applications. Previously, we demonstrated the possibility of using free-standing nanotube structures as reinforcing materials to support and guide neurite outgrowth making them potential candidates for extracellular implants. ${ }^{[30]}$ From a practical standpoint, both studies open the way to engineering of biomedical devices from SWNT films. Electrical stimulation has been shown to be involved in synaptogenesis, nerve repair, and cell survival in neurons and other electrically responsive tissue. ${ }^{[47-50]}$ Further research should be conducted to investigate the synaptic formation between different neuronal cells or between neuronal cells and other type of cells, such as muscle cells, on the surface of a carbon-nanotube platform.

\section{Experimental}

Film Preparation: In order to prepare the SWNT LBL films, SWNTs were surface-modified with an amphiphilic $\operatorname{poly}(N$-cetyl-4-vinylpyridinium bromide-co- $N$-ethyl-4-vinylpyridinium bromide-co-4-vinylpyridine) copolymer (generous gift of A. Yaroslavov) according to a previously reported protocol [38]. This macromolecule wraps around carbon nanotubes and renders them positively charged, which is considered to be an important structural feature of the SWNT/poly $(N$ cetyl-4-vinylpyridinium bromide-co- $N$-ethyl-4-vinylpyridinium bromide-co-4-vinylpyridine) colloid (denoted here as $\mathrm{SWNT}^{+}$) because it facilitates and accelerates both LBL deposition and cell adhesion [30]. SWNT LBL multilayers were constructed by alternating adsorption of $\mathrm{SWNT}^{+}$and the negatively charged poly(acrylic acid) $\left(\mathrm{PAA}^{-}\right)$following the standard LBL method [30]. The initial assembly started by dipping a glass slide in a $1 \%$ polydimethyldiallylammonium (PDDA) (weight-average molecular weight $M_{\mathrm{w}} \sim 400000-500000 \mathrm{~g} \mathrm{~mol}^{-1}$, Sigma-Aldrich) solution ( $\mathrm{pH} 6)$ for $10 \mathrm{~min}$ followed by rinsing with deionized water three times ( $1 \mathrm{~min} /$ rinse $)$. Alternating layers of PAA and $\mathrm{SWNTs}^{+}$were then constructed by dipping the PDDA-coated substrate in a $1 \%$ PAA $\left(M_{\mathrm{w}} \sim 450000\right.$, Sigma-Aldrich $)$ solution (pH6) for $10 \mathrm{~min}$, followed by rinsing with deionized water three times ( $3 \mathrm{~min} /$ rinse), and then dipping in SWNTs ${ }^{+}$for $1 \mathrm{~h}$, followed by rinsing with deionized water three times ( $1 \mathrm{~min} /$ rinse). 
Electrophysiology: Whole-cell recording pipettes were made from $1.5 \mathrm{~mm}$ OD 8515 glass (Warner Instruments) and pulled to a resistance of 2-5 M $\Omega$ using a Sutter Instruments P 87 puller. Electrode solutions contained $140 \mathrm{~mm}$ potassium gluconate, $2 \mathrm{~mm} \mathrm{MgCl}_{2}, 2 \mathrm{~mm}$ 1,2-bis(2-aminophenoxy)ethane- $N, N, N^{\prime}, N^{\prime}$-tetraacetic acid (BAPTA), $0.2 \mathrm{~mm} \mathrm{CaCl}_{2}$, and $1 \mathrm{~mm}$ 2-[4-(2-hydroxyethyl)-1-piperazinyl] ethanesulfonic acid (HEPES) of pH 7.4. Voltage-clamp protocols were controlled using HEKA Pulse (v. 8.54, HEKA Instruments Inc.). All cell currents were recorded in HEPES buffer saline (HBS; in mM: $130 \mathrm{NaCl}, 3 \mathrm{KCl}, 2 \mathrm{CaCl}_{2}, 1.2 \mathrm{MgCl}_{2}, 10$ HEPES (pH 7.3), 10 glucose).

Received: April 22, 2006 Revised: August 15, 2006

[1] R. Martel, T. Schmidt, H. R. Shea, T. Hertel, P. Avouris, Appl. Phys. Lett. 1998, 73, 2447.

[2] R. H. Baughman, C. Cui, A. A. Zakhidov, Z. Iqbal, J. N. Barisci, G. M. Spinks, G. G. Wallace, A. Mazzoldi, D. D. Rossi, A. Rinzler, O. Jaschinski, S. Roth, M. Kertesz, Science 1999, 284, 1340.

[3] T. Rueckes, K. Kim, E. Joselevich, G. Tseng, C. Cheung, C. M. Lieber, Science 2000, 289, 94.

[4] H. M. Manohara, E. W. Wong, E. Schlecht, B. D. Hunt, P. H. Siegel, Nano Lett. 2005, 5, 1469.

[5] Y. Zhou, A. Gaur, S.-H. Hur, C. Kocabas, M. A. Meitl, M. Shim, J. A. Rogers, Nano Lett. 2004, 4, 2031.

[6] A. Javey, J. Guo, D. B. Farmer, Q. Wang, E. Yenilmez, R. G. Gordon, M. Lundstrom, H. Dai, Nano Lett. 2004, 4, 1319.

[7] J. Kong, N. R. Franklin, C. Zhou, M. G. Chapline, S. Peng, K. Cho, H. Dai, Science 2000, 287, 622.

[8] P. Qi, O. Vermesh, M. Grecu, A. Javey, Q. Wang, H. Dai, S. Peng, K. J. Cho, Nano Lett. 2003, 3, 347.

[9] J. Li, Y. Lu, Q. Ye, M. Cinke, J. Han, M. Meyyappan, Nano Lett. 2003, 3, 929 .

[10] S. Chopra, K. McGuire, N. Gothard, A. M. Rao, A. Pham, Appl. Phys. Lett. 2003, 83, 2280.

[11] Q. Fu, J. Liu, J. Phys. Chem. B 2005, 109, 13406.

[12] C. Y. Lee, M. S. Strano, Langmuir 2005, 21, 5192.

[13] N. S. Lee, D. S. Chung, I. T. Han, J. H. Kang, Y. S. Choi, H. Y. Kim, S. H. Park, Y. W. Jin, W. K. Yi, M. J. Yun, J. E. Jung, C. J. Lee, J. H. You, S. H. Jo, C. G. Lee, J. M. Kim, Diamond Relat. Mater. 2001, 10, 265.

[14] Y. Saito, S. Uemura, Carbon 2000, 38, 169

[15] K. Besteman, J.-O. Lee, F. G. Wiertz, H. A. Heering, C. Dekker, Nano Lett. 2003, 3, 727.

[16] A. Star, J. P. Gabriel, K. Bradly, G. Gruner, Nano Lett. 2003, 3, 459.

[17] R. J. Chen, H. C. Choi, S. Bangsaruntip, E. Yenilmez, X. Tang, Q. Wang, Y. Chang, H. Dai, J. Am. Chem. Soc. 2004, 126, 1563.

[18] K. Bradley, M. Briman, A. Star, G. Gruner, Nano Lett. 2004, 4, 253.

[19] P. W. Barone, S. Baik, D. A. Heller, M. S. Strano, Nat. Mater. 2005 , 4,86 .

[20] D. Pantarotto, J. Briand, M. Prato, A. Pianco, Chem. Commun. 2004, 16
[21] N. Kam, T. C. Jessop, P. A. Wender, H. Dai, J. Am. Chem. Soc. 2004 126,6850 .

[22] Q. Lu, J. M. Moore, G. Huang, A. S. Mount, A. M. Rao, L. L. Larcom, P. C. Ke, Nano Lett. 2004, 4, 2473.

[23] P. Cherukuri, S. M. Bachilo, S. H. Litovsky, R. B. Weisman, J. Am. Chem. Soc. 2004, 126, 15638.

[24] A. Bianco, J. Hoebeke, S. Godefroy, O. Chaioin, D. Pantarotto, J.-P. Briand, S. Muller, M. Prato, C. D. Partidos, J. Am. Chem. Soc. 2005 , 127, 58.

[25] M. P. Mattson, R. C. Haddon, A. M. Rao, J. Mol. Neurosci. 2000, 14, 175 .

[26] H. Hu, Y. Ni, V. Montana, R. C. Haddon, V. Parpura, Nano Lett. 2004, 4, 507

[27] H. Hu, Y. Ni, S. K. Mandal, V. Montana, B. Zhao, R. C. Haddon, V. Parpura, J. Phys. Chem. B 2005, 109, 4285.

[28] T. J. Webster, M. C. Waid, J. L. McKenzie, R. L. Price, J. U. Ejiofor, Nanotechnology 2004, 15, 48.

[29] A. A. Mamedov, N. A. Kotov, M. Prato, D. M. Guldi, J. P. Wicksted, A. Hirsch, Nat. Mater. 2002, 1, 190.

[30] M. K. Gheith, V. A. Sinani, R. L. Matts, J. P. Wicksted, N. A. Kotov, Adv. Mater. 2005, 17, 2663.

[31] P. R. Supronowicz, P. M. Ajayan, K. R. Ullmann, B. P. Arulanandam, D. W. Metzger, R. Bizios, J. Biomed. Mater. Res. 2002, 5, 499.

[32] V. Lovat, D. Pantarotto, L. Lagostena, B. Cacciari, M. Grandolfo, M. Righi, G. Spalluto, M. Prato, L. Ballerini, Nano Lett. 2005, 5, 1107.

[33] A. Mamedov, N. A. Kotov, Langmuir 2000, 16, 5530

[34] Z. Tang, N. A. Kotov, S. Magonov, B. Ozturk, Nat. Mater. 2003, 2 , 413.

[35] C. Jiang, S. Markutsya, Y. Pikus, V. V. Tsukruk, Nat. Mater. 2004, 3, 721.

[36] J. Black, T. Baranowski, Jr., Bioelectrochem. Bioenerg. 1984, 12, 323.

[37] K. Yonernori, S. Matsunaga, Y. Ishidou, S. Maeda, H. Yoshido, Bone 1996, 19, 173.

[38] V. A. Sinani, M. K. Gheith, A. A. Yaroslavov, A. A. Rakhnyanskaya, S. Kai, A. A. Mamedov, J. P. Wicksted, N. A. Kotov, J. Am. Chem. Soc. 2005, 127, 3463 .

[39] B. S. Shim, N. A. Kotov, Langmuir 2005, 21, 9381.

[40] D. Braun, P. Fromherz, Phys. Rev. Lett. 2001, 86, 2905.

[41] M. Voelker, P. Fromherz, Small 2005, 1, 206.

[42] M. O'Donnell, M. Villereal, J. Cell. Physiol. 1982, 113, 405.

[43] H. Ammer, R. Schulz, Neurosci. Lett. 1997, 230, 143.

[44] B. Hille, Ion Channels of Excitable Membranes, Sinauer, Sunderland, MA 2001.

[45] B. Hamprecht, Int. Rev. Cytol. 1977, 49, 99.

[46] T. Furakawa, E. Furshpan, J. Neurophysiol. 1963, 26, 140.

[47] C. D. McCaig, A. M. Rajnicek, B. Song, M. Zhao, Trends Neurosci. 2002, 25, 354 .

[48] A. M. Rajnicek, K. R. Robinson, C. D. McCaig, Dev. Biol. 1998 $203,412$.

[49] T. A. Brosenitsch, D. M. Katz, J. Neurosci. 2001, 21, 2571.

[50] T. Hertzberg, T. Brosenitsch, D. M. Katz, Neuroreport 1995, 7, 233. 